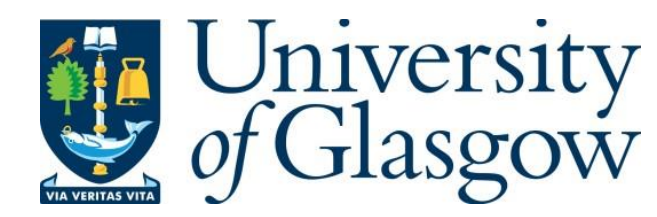

Lv, J., Tang, R., Jia, S. and Liu, Y. (2016) Experimental study on energy consumption of computer numerical control machine tools. Journal of Cleaner Production, 112, pp. 3864-3874.

There may be differences between this version and the published version. You are advised to consult the publisher's version if you wish to cite from it.

http://eprints.gla.ac.uk/145041/

Deposited on: 2 August 2017

Enlighten - Research publications by members of the University of Glasgow http://eprints.gla.ac.uk 


\title{
Experimental study on energy consumption of computer numerical control machine tools
}

\author{
Jingxiang $\mathrm{Lv}^{\mathrm{a}, \mathrm{c}}$, Renzhong Tang ${ }^{\mathrm{a}, *}$, Shun Jia ${ }^{\mathrm{a}, \mathrm{d}}$, Ying Liu ${ }^{\mathrm{b}}$ \\ ${ }^{a}$ Industrial Engineering Center, Zhejiang Province Key Laboratory of Advanced Manufacturing \\ Technology, Zhejiang University, Hangzhou 310027, Zhejiang, China. \\ ${ }^{\mathrm{b}}$ School of Aerospace, Transportation and Manufacturing, Cranfield University, Cranfield, MK43 \\ 0AL, United Kingdom. \\ ' Xi' an Research Institute of Navigation Technology, Xi'an 710068, Shaanxi, China. \\ ${ }^{\mathrm{d}}$ Shandong University of Science and Technology, Qingdao 266590, China \\ * Corresponding author: Renzhong Tang, Industrial Engineering Center, Zhejiang Province Key \\ Laboratory of Advanced Manufacturing Technology, Zhejiang University, Hangzhou 310027, \\ Zhejiang, China. \\ Email: tangrz@zju.edu.cn, Tel.: +86(0)57187952048
}

\begin{abstract}
Machining processes are responsible for substantial environmental impacts due to their great energy consumption. Accurately characterizing the energy consumption of machining processes is a starting point to increase manufacturing energy efficiency and reduce their associated environmental impacts. The energy calculation of machining processes depends on the availability of energy supply data of machine tools. However, the energy supply can vary greatly among different types of machine tools so that it is difficult to obtain the energy data theoretically. The aim of this research was to investigate the energy characteristics and obtain the power models of computer numerical control (CNC) machine tools through an experimental study. Four CNC lathes, two CNC milling machines and one machining center were selected for experiments. Power consumption of non-cutting motions and material removal were measured and compared for the selected machine
\end{abstract}


tools. Here, non-cutting motions include standby, cutting fluid spraying, spindle rotation and feeding operations of machine tools. Material removal includes turning and milling. Results show that the power consumption of non-cutting motions and milling is dependent on machine tools while the power consumption of turning is almost independent from the machine tools. The results imply that the energy saving potential of machining processes is tremendous.

Keywords: Energy consumption; Non-cutting motions; Material removal; Computer numerical control machine tools

\section{Introduction}

One of the most severe problems we currently face in the manufacturing industry is the energy consumption. Energy used by the industrial sector has more than doubled in the last 50 years and industry currently consumes about half of the world's energy (Mouzon et al., 2007). For example, in China, the energy used in manufacturing industry amounted 1,884,980,000 tons of coal equivalent and contributed to 58\% of China's total energy consumption in 2010 (NBS, 2011). Machining is widely used in the manufacturing sector (Hanafi et al., 2012). Improving the energy efficiency of machining processes can yield significant reduction in the environmental impact. In order to achieve this goal, the energy consumption of machining processes needs to be characterised and evaluated properly (Li and Kara, 2011).

The energy consumed during machining processes can be divided into two parts: constant energy consumed by non-cutting operations of the machine tool and material removal energy which is the actual energy used to remove material (Dahmus and Gutowski, 2004). Here, the non-cutting operations include standby, cutting fluid spraying, spindle rotation, feeding, etc. The non-cutting power can vary significantly among different types of machine tools. For instance, the standby power could range from $319 \mathrm{~W}$ to $4040 \mathrm{~W}$ for different types of machine tools (Behrendt et al., 2012). For operations such as spindle rotation and feeding, their power is also influenced by various operation parameters. A lot of current research has focused on the theoretically modeling of power consumption of machine tool operations. However, many unknown parameters in the theoretical 
models are difficult to obtain due to the complexity of computer numerical control (CNC) machine tools. Thus measurements are necessary to obtain the power models with statistical analysis.

CNC machine tools are complex electromechanical products with multiple energy sources and energy flow links. There are many types of CNC machine tools, including CNC lathes, CNC milling machines, $\mathrm{CNC}$ grinding machines, machining centers. Each type of $\mathrm{CNC}$ machine tool also contains a wide variety of machines. There are many differences in the mechanical structure, motor performance and motion control for different machine tools. Thus energy supply characteristics may vary a lot for different CNC machine tools.

The aim of this study is to obtain the power models of machine tool motions based on the measured power data and statistical analysis, and to investigate the energy saving potential of CNC machine tools. The structure of this paper is as follows. In part 2 a review of current modeling approaches for energy supply is carried out. In part 3, experiments are conducted on different machine tools to obtain the power data of various motions. In part 4, based on the measurement results, power of non-cutting motions and material removal was modeled and discussed. In addition, specific energy consumption and energy utilization rate were discussed to explore energy saving opportunities. Finally in part 5 the conclusions are drawn and future work is discussed.

\section{Literature review}

\subsection{Motions of the machine tools during machining processes}

Machine tools consume most of the energy in machining system. During machining processes, the tasks are completed through a series of machine tool motions which consume energy. When the machine tool is turned on, the control system, spindle system and servo system are in a state of readiness. This state of readiness, which is called basic motion, is the basis of other motions and exists throughout the whole process of machine tool operation. The motions used to generate the surface of product are called generation motions, which include the primary motion and feed motion (Knight and Boothroyd, 2006). The energy consumption of generation motions can be divided into two categories, energy consumed by air-cutting motions and energy consumed by material removal. 
The air-cutting motions, which include spindle rotation and feeding, are the generation motions without cutting load. In addition to basic motion and generation motions, there exists other motions to assist the cutting operations, including cutting fluid spraying, automatic tool changing (ATC) and so on, such kind of motions are called auxiliary motions. According to the above analysis, the motions of machine tool can be categorized into four types, as shown in Table 1.

Table 1 Motions of CNC machine tools

\begin{tabular}{|c|c|c|}
\hline Type & Name & Description \\
\hline Basic motion & Basic Motion & Standby operation of the machine tool \\
\hline & Cutting Fluid Spraying & Spray the coolant fluid onto the cutting area \\
\hline Auxiliary motion & Automatic Tool Changing & Convert one cutting tool to another automatically \\
\hline Air-cutting & Spindle Rotation & Spindle rotate at a certain speed \\
\hline motion & Feeding & Feed in $\mathrm{X} / \mathrm{Y} / \mathrm{Z}$ axis \\
\hline Material removal & Cutting & $\begin{array}{l}\text { The cutting tool contact the workpiece and } \\
\text { remove the material }\end{array}$ \\
\hline
\end{tabular}

\subsection{Energy consumption of basic and auxiliary motion}

The power of basic motion, which is also called standby power, is usually obtained through measurements. The measurement results of commercial press-brake showed that the basic motion consumed $43 \%, 27 \%$ and $83 \%$ of the total energy for three machine tools, respectively (Santos et al., 2011). The standby power of nine different CNC machine tools was measured and results showed that it varied significantly across different machine tools, ranging from $319 \mathrm{~W}$ up to $4040 \mathrm{~W}$ (Behrendt et al., 2012). Results also showed that the standby power increased with the complexity of a machine tool, for the reason that the realization of high automation of machine tools needs more auxiliary functions (such as hydraulic systems and cooling systems), resulting in greater energy consumption for basic motion. Similar researches were carried out by Li et al. (2011), the standby power of two CNC grinding machines, a CNC lathe, a CNC lathe with milling functionality, a vertical milling machining center and a 5-axis machining center were measured, ranging from 1020 $\mathrm{W}$ to $5450 \mathrm{~W}$. It can be seen that the standby power of different CNC machine tools varies a lot. Most of the machine tools being studied in literature are highly automated machines produced in European and American. These machines contain complex hydraulic and cooling systems, resulting in large standby power consumption. In China, many low-end machine tools produced are currently used (Li, 2014). However, there are few studies on the standby power of these machines. 
The auxiliary motions include cutting fluid spraying and ATC. The cutting fluids are indispensible for many cutting processes, it can help cool the tool and workpiece, reduce friction between the tool edge and workpiece in order to extend tool life and improve workpiece surface quality (Rao, 2000). However, the usage of cutting fluids could result in increased energy costs, environmental pollution and human chronic diseases, in addition, it consumes extra power used by the coolant pump motor to spray the coolant onto the tool and workpiece. Murray et al. (2012) measured the energy consumption of Huffman HS-155R multi-axis grinding machines, in which $34 \%$ of the total energy is consumed by cutting fluid spraying. The power of coolant pump motor for PL700 vertical machining center is measured to be $340 \mathrm{~W}$. The energy consumption of cutting fluid spraying accounted for $23 \%$ of the total energy consumption during the machining processes (Li et al., 2013). Cutting fluid spraying accounts for a large proportion of total energy consumption during machining, and its power consumption can be obtained experimentally. The automatic tool change system can automatically convert one tool to another, thus shortening auxiliary time between adjacent steps. Tool changing lasts a relatively short time. For instance, it lasts for 3.0-4.1 s for CK6153i CNC lathe (Lv et al., 2014). The energy consumption of ATC is insignificant, thus the energy consumption of ATC is excluded in this study.

\subsection{Energy consumption of air-cutting motion}

The air-cutting motion is the machine tool running with no load, including spindle rotation and feeding. Spindle rotation is one of the largest energy consuming motions. The power of spindle rotation and feeding has been modeled theoretically by some researchers. The mechanical energy requirement of the spindle was estimated by multiplying the angular speed and the torque (Avram and Xirouchakis, 2011). In Avram's model, both the steady state and transient regimes of the spindle are considered, but the electrical losses are ignored, as a result, the predicted power is only about 50\% of the actual power. The power of spindle rotation is expressed as a linear function of the spindle rotational speed (Jia et al., 2013; Li and Kara, 2011). In this model, the power increases with the spindle rotational speed, yet this is not always the case. However, for the commonly used frequency control spindle motor, when it runs beyond the base frequency, the power loss of the motor is subject to a slight decrease with the increase of spindle rotational speed (Avram and Xirouchakis, 2011). For 
this reason, piecewise linear function has been used to describe the spindle rotational power (Balogun and Mativenga, 2013), and a generic model was formulated as follows:

$$
P_{\mathrm{SR}}=m n+C
$$

Where, $P_{\mathrm{SR}}$ is the spindle rotation power $[\mathrm{W}], m$ is the coefficient of spindle rotational speed, $n$ is the spindle rotational speed $[\mathrm{r} / \mathrm{min}]$, and $C$ is a constant.

Feed drive, which is used to position the machine tool and workpiece, is an integral subsystem of machine tools. The positioning accuracy and feed speed determine the surface quality of machined parts and production efficiency. The power of feeding is a function of feed rate. The power of feeding at certain feed rate was measured. Take the PL700 vertical-milling machine centre made by Chengdu Precise CNC Machine Tool of China for example, the power of X, Y and Z-axis feeding was measured to be $15 \mathrm{~W}, 15 \mathrm{~W}$ and $32 \mathrm{~W}$ (He et al., 2012). Lv et al. modeled the power of feeding to be quadratic function of feed rate through theoretical analysis of machine tools feed drive structure (Lv et al., 2014). The model is expressed as:

$$
P_{\mathrm{FD}}=C_{1} \times f_{r}+C_{2} \times f_{r}^{2}
$$

Where, $P_{\mathrm{FD}}$ is the power of axis feeding [W], $f_{r}$ is feed rate $[\mathrm{mm} / \mathrm{min}], C_{1}$ and $C_{2}$ are coefficients.

\subsection{Energy consumption of material removal}

The power of material removal is the actual power used to remove material. There are good theoretical computations available for cutting energy, but they are difficult to perform due to the difficulties in the calculation of all the parameters involved in the theoretical formulas (Kalpakjian, 1984). The empirical method is, therefore, still widely used for the reliable prediction of cutting forces and energies (Bhushan, 2013; Ding et al., 2010). Empirical models possess simple and easy-to-get characteristics as well as provide high prediction accuracy. Hence, generic exponential models are chosen to describe the relationship between the material removal power and the process parameters. The material removal power models were derived by multiplying cutting force by cutting speed. Here, the cutting force models were from Ai and Xiao (1994). For turning processes:

$$
P_{\mathrm{T}}=C_{\mathrm{T}} a_{\mathrm{p}}^{x_{\mathrm{T}}} f^{y_{\mathrm{T}}} v^{n_{\mathrm{T}}}
$$


Where, $P_{\mathrm{T}}$ is the turning power $[\mathrm{W}], \quad a_{\mathrm{p}}$ is the depth of cut $[\mathrm{mm}], f$ is feed $[\mathrm{mm} / \mathrm{r}], v$ is the cutting speed $[\mathrm{m} / \mathrm{min}], C_{\mathrm{T}}, x_{\mathrm{T}}, y_{\mathrm{T}}$ and $n_{\mathrm{T}}$ are coefficients of the turning power, depth of cut, feed rate and cutting speed, respectively.

Likewise, for milling processes:

$$
P_{\mathrm{M}}=C_{\mathrm{M}} a_{\mathrm{p}}^{x_{\mathrm{M}}} f_{\mathrm{z}}^{y_{\mathrm{M}}} v^{n_{\mathrm{M}}} a_{\mathrm{e}}^{u_{\mathrm{M}}}
$$

Where, $P_{\mathrm{M}}$ is the milling power $[\mathrm{W}], a_{\mathrm{p}}$ is the depth of cut $[\mathrm{mm}], f_{\mathrm{z}}$ is feed per tooth $[\mathrm{mm} /$ tooth $], v$ is the cutting speed $[\mathrm{m} / \mathrm{min}], a_{\mathrm{e}}$ is the width of cut $[\mathrm{mm}], C_{\mathrm{M}}, x_{M}, y_{\mathrm{M}}, n_{\mathrm{M}}$ and $u_{\mathrm{M}}$ are coefficients of the milling power, depth of cut, feed rate per tooth, cutting speed and width of cut, respectively.

The power during machining can be easily measured by power monitor, such as a wattmeter (Kalpakjian and Schmid, 2006), thus the material removal power could be directly modeled through power measurements and multiple linear regression analysis.

\section{Methodology}

Experiments were conducted to obtain the power data of machine tool motions at different operating parameters. The obtained data were further used for statistical analysis to acquire the power models of machine tool motions.

\subsection{Experimental setup}

Seven different CNC machine tools were selected to study the power characteristics of different motions. The machine tools used were including four CNC lathes (CK6153i, CK6136i, CAK6150Di and CY-K500), two CNC milling machines (JTVM6540 and XK715B) and a vertical milling center (XHK-714F). All of these machine tools were manufactured in China. The technical specification parameters of the seven selected machines are listed in Table 2 and Table 3. 
Table 2 Technical specification parameters of the selected lathes.

\begin{tabular}{lllll}
\hline Parameter & CK6136i & CK6153i & CAK6150Di & CY-K500 \\
\hline Max. turning diameter $[\mathrm{mm}]$ & 360 & 530 & 610 & 500 \\
Max. travel range X×Z [mm×mm] & $160 \times 200$ & $260 \times 400$ & $305 \times 600$ & $250 \times 880$ \\
Max. spindle speed $[\mathrm{r} / \mathrm{min}]$ & 3000 & 2000 & 1500 & 2500 \\
Rapid traverse rate $[\mathrm{m} / \mathrm{min}]$ & $\mathrm{X}: 3 \mathrm{Z}: 4$ & $\mathrm{X}: 4 \mathrm{Z}: 8$ & $\mathrm{X}: 5 \mathrm{Z}: 10$ & $\mathrm{X}: 4 \mathrm{Z}: 8$ \\
Number of tool stations & 4 & 4 & 4 & 4 \\
\hline
\end{tabular}

Table 3 Technical specification parameters of the selected CNC milling machines and machining center.

\begin{tabular}{|c|c|c|c|}
\hline \multirow{2}{*}{ Parameter } & \multicolumn{2}{|c|}{ CNC milling machines } & \multirow{2}{*}{$\begin{array}{l}\text { Machining center } \\
\text { XHK-714F }\end{array}$} \\
\hline & JTVM6540 & XK715B & \\
\hline $\begin{array}{l}\text { Max. travel range } \mathrm{X} \times \mathrm{Y} \times \mathrm{Z} \\
{[\mathrm{mm} \times \mathrm{mm} \times \mathrm{mm}]}\end{array}$ & $650 \times 370 \times 400$ & $1320 \times 550 \times 600$ & $650 \times 400 \times 480$ \\
\hline Max. spindle speed [r/min] & 6000 & 1600 & 6000 \\
\hline Rapid traverse rate $[\mathrm{m} / \mathrm{min}]$ & $X: 6 ~ Y: 6 ~ Z: 6$ & $X: 10 ~ Y: 10 ~ Z: 10$ & $\mathrm{X}: 12 \mathrm{Y}: 12 \mathrm{Z}: 10$ \\
\hline Capacity of the tool magazine & - & - & 8 \\
\hline
\end{tabular}

Table 4 Workpiece material details.

\begin{tabular}{ll}
\hline & AISI 1045 steel \\
\hline Yield strength (Mpa) & 385 \\
Tensile strength (Mpa) & 665 \\
Elongation (\%) & $24.5 / 25$ \\
Hardness (HB) & 262 \\
Chemical composition (wt \%) & $\mathrm{C}(0.44) ; \mathrm{Si}(0.23) ; \mathrm{Mn}(0.61) ; \mathrm{P}(0.012) ; \mathrm{S}(0.024) ; \mathrm{Ni}(0.02) ;$ \\
\hline
\end{tabular}

Table 5 Workpiece size and tool conditions used in the experiments.

\begin{tabular}{lll}
\hline & Turning & Milling \\
\hline Workpiece size & $\varnothing 80 \mathrm{~mm} \times 150 \mathrm{~mm}$ & $100 \mathrm{~mm} \times 60 \mathrm{~mm}$ \\
& & \\
Insert & VNMG160408-YBC351 & - \\
Tool holder & MVJNR2525M16 & BT40 \\
Clearance angle & $0^{\circ}$ & - \\
Cutting edge angle & $93^{\circ}$ & - \\
Nose radius & $0.8 \mathrm{~mm}$ & - \\
Tool diameter & - & $14 \mathrm{~mm}$ \\
Number of cutting edges & - & 4 \\
Total length of the tool & - & $100 \mathrm{~mm}$ \\
Height of the cutter & - & $35 \mathrm{~mm}$ \\
Tool manufacturer & Sumitomo & Jiaxing Yongtuo \\
\hline
\end{tabular}

For cutting tests, AISI 1045 steel was selected as the test material because of its wide use in manufacturing industry. Further details of the workpiece materials are shown in Table 4 . The cutting inserts were recommended by the tool manufacturer. The workpiece size and tool conditions are 
presented in Table 5. The test cutting fluid was a commonly used water-based emulsion which has a consistency of 1 part oil to 50 parts water.

During each test, the total electrical power consumption was measured using three voltage transducers LEM LV25-P and three current transducers LEM LA55-P which were connected to the main bus of the electrical cabinet of the machine tools. The voltage signal is acquired and sampled by using two NI-9215 data acquisition cards and a compact NI Cdaq-9174 data acquisition chassis at a sampling frequency of $5000 \mathrm{~Hz}$ per channel. The LabVIEW programming interface was developed to visualize and store the acquired force and power data. The power values of the machine tool were recorded once every $0.1 \mathrm{~s}$, as shown in Fig. 1.

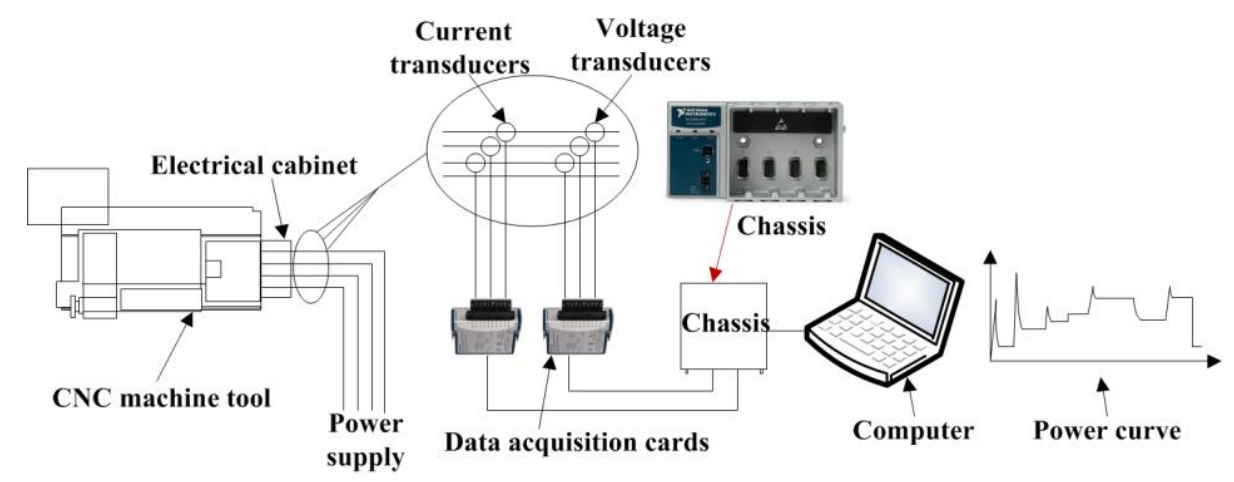

Fig. 1. Schematic diagram of the experimental set-up.

The power of basic motion and cutting fluid spraying was constant and obtained through measurement. The power of spindle rotation, feeding and cutting varies with different process parameters. For spindle rotation experiments, the speed ranges were determined, and then the spindle was controlled to rotate at each same interval in the ranges. For instance, the spindle rotating speed has been defined within a range from 0 to $1500 \mathrm{rpm}$ during the spindle rotation experiment. The spindle was rotating at the speed of $100,200,300, \ldots, 1500 \mathrm{rpm}$. The feed axis was operated by the same experiment approach. Cutting experiments were conducted with different combination of cutting parameters using design of experiments which will be elaborated in section 3.2. All experiments were repeated three times and the average values of the three measurements of were used in the paper. 


\subsection{Design of experiments for cutting tests}

For cutting tests, design of experiments (DOE) was chosen to plan the experiments. Taguchi's orthogonal design was employed to study the factors that influence the cutting power. The value of turning power is decided by values of parameters including cutting speed, feed and depth of cut. Hence, the three parameters can be defined as process variables. As presented in Table 6, four levels of cutting speed, feed and depth of cut were selected from the tool manufacturers' recommendation. The design matrix for turning experiments is shown in Table 7. As shown in the matrix in Table 7, each row represents one trial. 16 experiments were conducted under dry conditions. The length of cut for each test was $30 \mathrm{~mm}$ in axial direction.

Table 6 Cutting parameters and their levels in turning experiments.

\begin{tabular}{lllll}
\hline Cutting parameters & Level 1 & Level 2 & Level 3 & Level 4 \\
\hline Cutting speed $[\mathrm{m} / \mathrm{min}]$ & 50 & 100 & 150 & 200 \\
Feed $[\mathrm{mm} / \mathrm{rev}]$ & 0.05 & 0.1 & 0.15 & 0.2 \\
Depth of cut [mm] & 0.5 & 1.0 & 1.5 & 2.0 \\
\hline
\end{tabular}

Table 7 Design matrix for turning experiments.

\begin{tabular}{cccc}
\hline \multirow{2}{*}{$\begin{array}{c}\text { Experiment } \\
\text { al order }\end{array}$} & \multicolumn{3}{c}{ Cutting parameters } \\
\cline { 2 - 4 } & $\begin{array}{c}\text { Cutting speed } \\
{[\mathrm{m} / \mathrm{min}]}\end{array}$ & $\begin{array}{l}\text { Feed } \\
{[\mathrm{mm} / \mathrm{rev}]}\end{array}$ & $\begin{array}{c}\text { Depth of } \\
\text { cut }[\mathrm{mm}]\end{array}$ \\
\hline 1 & 50 & 0.05 & 0.5 \\
2 & 50 & 0.1 & 1 \\
3 & 50 & 0.15 & 1.5 \\
4 & 50 & 0.2 & 2 \\
5 & 100 & 0.05 & 1 \\
6 & 100 & 0.1 & 0.5 \\
7 & 100 & 0.15 & 2 \\
8 & 100 & 0.2 & 1.5 \\
9 & 150 & 0.05 & 1.5 \\
10 & 150 & 0.1 & 2 \\
11 & 150 & 0.15 & 0.5 \\
12 & 150 & 0.2 & 1 \\
13 & 200 & 0.05 & 2 \\
14 & 200 & 0.1 & 1.5 \\
15 & 200 & 0.15 & 1 \\
16 & 200 & 0.2 & 0.5 \\
\hline
\end{tabular}

In milling tests, cutting speed, feed per tooth, depth of cut and width of cut were selected as the process variables. As presented in Table 8, four levels of cutting speed, feed, depth of cut and width 
of cut were selected from the tool manufacturers' recommendation. The design matrix for milling experiments is shown in Table 9. 16 experiments were conducted under wet conditions. The length of cut for each test was $60 \mathrm{~mm}$.

Table 8 Cutting parameters and their levels in milling experiments.

\begin{tabular}{lllll}
\hline Cutting parameters & Level 1 & Level 2 & Level 3 & Level 4 \\
\hline Cutting speed [m/min] & 60 & 80 & 100 & 120 \\
Feed per tooth[mm/tooth] & 0.03 & 0.06 & 0.09 & 0.12 \\
Depth of cut [mm] & 0.5 & 1 & 1.5 & 2 \\
Width of cut [mm] & 6 & 8 & 10 & 12 \\
\hline
\end{tabular}

Table 9 Design matrix for milling experiments.

\begin{tabular}{ccccc}
\hline \multirow{2}{*}{$\begin{array}{c}\text { Experimental } \\
\text { order }\end{array}$} & $\begin{array}{c}\text { Cutting speed } \\
{[\mathrm{m} / \mathrm{min}]}\end{array}$ & $\begin{array}{l}\text { Feed } \\
{[\mathrm{mm} / \mathrm{rev}]}\end{array}$ & $\begin{array}{c}\text { Depth of } \\
\text { cut }[\mathrm{mm}]\end{array}$ & $\begin{array}{c}\text { Width of } \\
\text { cut }[\mathrm{mm}]\end{array}$ \\
\cline { 2 - 5 } 1 & 60 & 0.03 & 0.5 & 6 \\
2 & 60 & 0.06 & 1 & 8 \\
3 & 60 & 0.09 & 1.5 & 10 \\
4 & 60 & 0.12 & 2 & 12 \\
5 & 80 & 0.03 & 1.5 & 12 \\
6 & 80 & 0.06 & 2 & 10 \\
7 & 80 & 0.09 & 0.5 & 8 \\
8 & 80 & 0.12 & 1 & 6 \\
9 & 100 & 0.03 & 2 & 8 \\
10 & 100 & 0.06 & 1.5 & 6 \\
11 & 100 & 0.09 & 1 & 12 \\
12 & 100 & 0.12 & 0.5 & 10 \\
13 & 120 & 0.03 & 1 & 10 \\
14 & 120 & 0.06 & 0.5 & 12 \\
15 & 120 & 0.09 & 2 & 6 \\
16 & 120 & 0.12 & 1.5 & 8 \\
\hline
\end{tabular}

The power of turning or milling is obtained by subtracting the measured idle power after cutting from the total power when the machine tool is cutting material. Take CK6153i for instance, power profile of turning is shown in Fig. 2. For cutting experiments, each run was repeated three times and the average values of cutting power were used in the paper. 


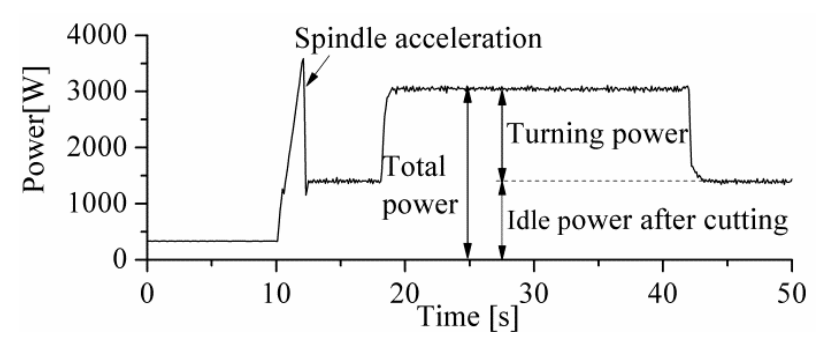

Fig. 2. Power profiles of turning for CK6153i.

\subsection{Regression analysis of cutting power models}

Regression analysis was used to obtain the cutting power models. The nonlinear Equation (3) for turning power can be converted into linear form by logarithmic transformation and can be written in Equation (5):

$$
\log \left(P_{\mathrm{T}}\right)=\log \left(C_{\mathrm{T}}\right)+n_{\mathrm{T}} \log (v)+y_{\mathrm{T}} \log (f)+x_{\mathrm{T}} \log \left(a_{\mathrm{p}}\right)
$$

The above Equation (5) can be written as follows:

$$
p_{\mathrm{T}}=c_{\mathrm{T}}+n_{\mathrm{T}} V+y_{\mathrm{T}} F+x_{\mathrm{T}} A_{\mathrm{p}}
$$

Where, $p_{\mathrm{T}}$ is the logarithmic transformation of the output power $P_{\mathrm{T}} ; V, F$ and $A_{\mathrm{p}}$, are the logarithmic transformation of the input parameters $v, f$ and $a_{\mathrm{p}} ; c_{\mathrm{T}}, n_{\mathrm{T}}, y_{\mathrm{T}}$ and $x_{\mathrm{T}}$ are the unknown coefficients to be estimated.

The above unknown coefficients $c_{\mathrm{T}}, n_{\mathrm{T}}, y_{\mathrm{T}}$ and $x_{\mathrm{T}}$ were acquired by multiple linear regressions of the experimental data using SPSS software. Then the turning power model can be obtained by substituting the acquired coefficients into Equation (3).

Likely, the milling power models of Equation (4) can be converted into linear form by logarithmic transformation as shown in Equation (7):

$$
\log \left(P_{\mathrm{M}}\right)=\log \left(C_{\mathrm{M}}\right)+x_{\mathrm{M}} \log \left(a_{\mathrm{p}}\right)+y_{\mathrm{M}} \log \left(f_{\mathrm{z}}\right)+n_{\mathrm{M}} \log (v)+u_{\mathrm{M}} \log \left(a_{\mathrm{e}}\right)
$$

The above Equation (7) can be written as follows:

$$
p_{\mathrm{M}}=c_{\mathrm{M}}+x_{\mathrm{M}} A_{\mathrm{p}}+y_{\mathrm{M}} F_{\mathrm{z}}+n_{\mathrm{M}} V+u_{\mathrm{M}} A_{\mathrm{e}}
$$


Where, $p_{\mathrm{M}}, A_{\mathrm{p}}, F_{\mathrm{z}}, V$ and $A_{\mathrm{e}}$ are the logarithmic transformation of $P_{\mathrm{M}}, a_{\mathrm{p}}, f_{\mathrm{z}}, v$ and $a_{\mathrm{e}} ; c_{\mathrm{M}}, x_{\mathrm{M}}$, $y_{\mathrm{M}}, n_{\mathrm{M}}$ and $u_{\mathrm{M}}$ are the unknown parameters to be estimated.

Based on the above Equation (8), the milling power model can be obtained through multiple linear regression analysis of experimental data using SPSS software.

\section{Results and discussion}

\subsection{Power of basic, auxiliary and air-cutting motions}

The basic, auxiliary and air-cutting motions are non-cutting motions of machine tools. Take CK6153i for example, its power profiles of basic motion and cutting fluid spraying is shown in Fig.

3. The measured power values of basic motion and cutting fluid spraying are shown in Table 10.

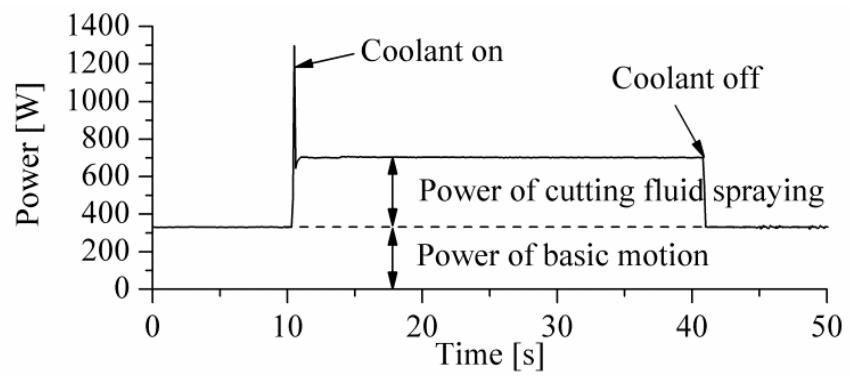

Fig. 3. Power profiles of basic motion and cutting fluid spraying for CK6153i.

Table 10 Measured power of basic motion and cutting fluid spraying.

\begin{tabular}{llllllll}
\hline & \multicolumn{7}{c}{ Machine tools } \\
\cline { 2 - 8 } Power & CK615 & CK613 & CAK615 & CY-K5 & JTVM6 & XK715 & XHK-71 \\
& $3 \mathrm{i}$ & $6 \mathrm{i}$ & 0Di & 00 & 540 & $\mathrm{~B}$ & 4F \\
\hline Basic motion [W] & 332.1 & 335.7 & 414.0 & 220.5 & 360.5 & 684.7 & 371.0 \\
Cutting fluid spraying [W] & 369.5 & 132.2 & 149.5 & 94.9 & 216.4 & 180.6 & 233.0 \\
\hline
\end{tabular}

The spindle rotational speed of CNC machine tool is controlled by variable frequency motor. In order to increase the output torque range of spindle system, the CNC lathes are often equipped with 2-4 transmission chains. For the selected CNC lathes, CK6153i has four transmission chains, from high-speed to low-speed they are $\mathrm{AH}, \mathrm{BH}, \mathrm{AL}$ and BL; CK6136i has two transmission chains: 
high-speed $(\mathrm{H})$ and low-speed (L); CAK6150Di and CY-K500 have three transmission chains: high-speed (H), medium-speed (M) and low-speed (L).
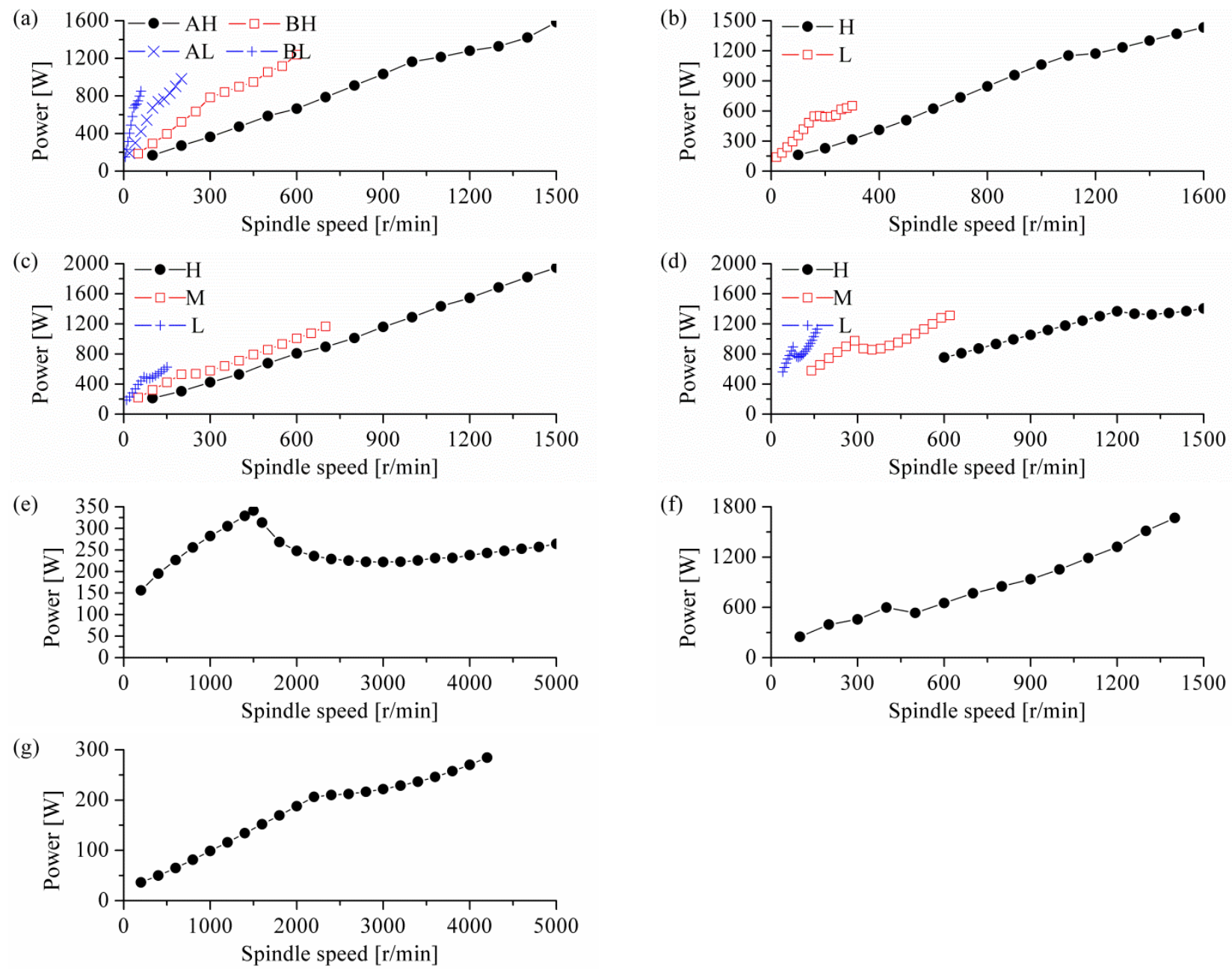

Fig. 4. Power of spindle rotation at various speeds: (a) CK6153i; (b) CK6136i; (c) CAK6150Di; (d) CY-K500; (e) JTVM6540; (f) XK715B; (g) XHK-714F.

The power curves of spindle rotation at various speeds are shown in Fig. 4. Compared to CNC lathes, CNC milling machines and machining center can achieve higher spindle rotational speeds. At the same speed, the power of spindle rotation for CNC milling machines and machining centers is much less than that of CNC lathes. The spindle system of CNC lathes has many transmission apparatus, including belts, shafts, gears, spindle and chuck, and the transmission apparatus weight of CNC lathe is much more than that of $\mathrm{CNC}$ milling machines and machining center. As a result, the spindle friction torque of lathes is larger than that of milling machines, and much more power is consumed by $\mathrm{CNC}$ lathes during spindle rotation at the same speed. For CNC lathes, the power of spindle 
rotation with different power transmission chains varies considerably. The power consumption at low-speed transmission chains is much larger than that at high-speed transmission chains to keep the spindle rotating at a certain speed, since the motor needs to rotate faster to drive the spindle rotating at low-speed transmission chains.

Table 11 Spindle rotation power prediction models.

\begin{tabular}{|c|c|c|c|}
\hline $\begin{array}{l}\text { Machi } \\
\text { ne tool }\end{array}$ & Power models & $\begin{array}{l}\text { Machi } \\
\text { ne tool }\end{array}$ & Power models \\
\hline \multirow{14}{*}{$\begin{array}{l}\text { CK615 } \\
3 \mathrm{i}\end{array}$} & $P_{\mathrm{SR}}^{\mathrm{AH}}$ & \multirow{8}{*}{$\begin{array}{l}\text { CK613 } \\
6 \mathrm{i}\end{array}$} & $P_{\mathrm{SR}}^{\mathrm{H}}$ \\
\hline & $(1.09 n+41.12 \quad(0<n \leq 1000)$ & & $(1.029 n+19.37$ \\
\hline & $=\left\{\begin{array}{l}0.558 n+605.05 \quad(1000<n \leq 1300) \\
\text {. }\end{array}\right.$ & & $=\{0.189 n+945.03$ \\
\hline & $1.288 n-358.21$ & & $0.656 n+383.72$ \\
\hline & $P_{\mathrm{SR}}^{\mathrm{BH}}$ & & $P_{\mathrm{SR}}^{\mathrm{L}}$ \\
\hline & \multirow{3}{*}{$= \begin{cases}2.37 n+55.46 & (0<n \leq 300) \\
1.10 n+455.37 & (300<n \leq 450) \\
1.87 n+109.64 & (450<n \leq 600)\end{cases}$} & & $(2.952 n+67.35 \quad(0<n \leq 160)$ \\
\hline & & & $=\left\{\begin{array}{l}-0.105 n+566.43(160<n \leq 220) \\
\text {. }\end{array}\right.$ \\
\hline & & & $(1.432 n+228.17 \quad(220<n \leq 300)$ \\
\hline & \multirow{4}{*}{$\begin{array}{l}P_{\mathrm{SR}}^{\mathrm{AL}} \\
=\left\{\begin{aligned} 6.04 n+64.30 & (0<n \leq 100) \\
2.31 n+449.87 & (100<n \leq 140) \\
3.61 n+257.28 & (140<n \leq 200)\end{aligned}\right.\end{array}$} & \multirow{9}{*}{$\begin{array}{l}\text { CY-K5 } \\
00\end{array}$} & $P_{\mathrm{SR}}^{\mathrm{H}}$ \\
\hline & & & $(1.03 n+133.87 \quad(600<n \leq 1200)$ \\
\hline & & & $-0.36 n+1793.3(1200<n \leq 1320)$ \\
\hline & & & $0.73 n+327.58 \quad(1320<n \leq 1800)$ \\
\hline & $P_{\mathrm{SR}}^{\mathrm{BL}}$ & & $(2.67 n+204.59 \quad(140<n \leq 290)$ \\
\hline & $=\left\{\begin{array}{cc}17.53 n+56.16 & (0<n \leq 35) \\
4.62 n+513.43 & (35<n \leq 50) \\
10.28 n+233.68 & (50<n \leq 60)\end{array}\right.$ & & $P_{\mathrm{SR}}^{\mathrm{M}}=\left\{\begin{array}{cc}-2.00 n+1540.2 & (290<n \leq 350) \\
1.82 n+176.23 & (350<n \leq 620)\end{array}\right.$ \\
\hline \multirow{5}{*}{$\begin{array}{l}\text { CAK6 } \\
\text { 150Di }\end{array}$} & \multirow{3}{*}{$\begin{array}{l}P_{\mathrm{SR}}^{\mathrm{H}}=1.255 n+46.07 \quad(0<n \leq 1500) \\
P_{\mathrm{SR}}^{\mathrm{M}}=\left\{\begin{array}{rc}2.067 n+114.86 & (0<n \leq 200) \\
0.125 n+504.22 & (200<n \leq 250) \\
1.465 n+130.31 & (250<n \leq 700)\end{array}\right.\end{array}$} & & $P_{\mathrm{SR}}^{\mathrm{L}}$ \\
\hline & & & $(9.17 n+198.95$ \\
\hline & & & $=\left\{\begin{array}{cl}-7.52 n+1444.2 & (76<n \leq 94) \\
5.80 n+170.8 & (94<n \leq 160)\end{array}\right.$ \\
\hline & $P_{\mathrm{SR}}^{\mathrm{L}}$ & & $P_{\mathrm{SR}}$ \\
\hline & $=\left\{\begin{array}{c}5.22 n+129.59 \\
-0.943 n+557.18 \\
2.548 n+237.55\end{array}\right.$ & $\begin{array}{l}\text { JTVM } \\
6540\end{array}$ & $=\left\{\begin{array}{cc}0.139 n+138.22 & (0<n \leq 15 C \\
-0.0723 n+415.99 & (1500<n \leq 3000) \\
0.0215 n+153.46 & (3000<n \leq 5000)\end{array}\right.$ \\
\hline & $P_{\mathrm{SR}}$ & & $P_{\mathrm{SR}}$ \\
\hline XHK-7 & $(0.086 n+14.76$ & XK715 & $(100<n \leq 400)$ \\
\hline \multirow[t]{2}{*}{$14 \mathrm{~F}$} & $=\left\{\begin{array}{l}0.0186 n+164.97(2200<n \leq 3000)\end{array}\right.$ & B & $(400<n \leq 500)$ \\
\hline & $(0.0522 n+61.62 \quad(3000<n \leq 4200)$ & & $1.22 n-110.18 \quad(500<n \leq 1400)$ \\
\hline
\end{tabular}

$n$ : Spindle rotational speed $[\mathrm{rpm}] ; P_{\mathrm{SR}}^{\mathrm{AH}}:$ Spindle rotation power for $\mathrm{AH}$ transmission chain $[\mathrm{W}] ; P_{\mathrm{SR}}^{\mathrm{BH}}:$ Spindle rotation power for $\mathrm{BH}$ transmission chain $[\mathrm{W}] ; P_{\mathrm{SR}}^{\mathrm{AL}}$ : Spindle rotation power for AL transmission chain $[\mathrm{W}] ; P_{\mathrm{SR}}^{\mathrm{BL}}$ : Spindle rotation power for $\mathrm{BL}$ transmission chain $[\mathrm{W}] ; P_{\mathrm{SR}}^{\mathrm{H}}$ : Spindle rotation power for $\mathrm{H}$ transmission chain $[\mathrm{W}] ; P_{\mathrm{SR}}^{\mathrm{M}}$ : Spindle rotation power for $\mathrm{M}$ transmission chain $[\mathrm{W}] ; P_{\mathrm{SR}}^{\mathrm{L}}$ : Spindle rotation power for $\mathrm{L}$ transmission chain $[\mathrm{W}]$. 
According to Equation (1), different models can be developed through piecewise linear regression to predict spindle rotation power during air-cutting motions, which are provided in Table 11. The cut-off points in the piecewise models were the corresponding spindle rotational speeds when the slope of the power curves changes significantly in Fig. 4.

The power curves of feeding at various feed rates are shown in Fig. 5. The feeding power of CNC milling machines and machining centers is greater than that of CNC lathe. Because the table of CNC milling machines and machining centers weight more, resulting in greater friction during feeding motion. The power of Z-axis feeding upward is greater than Z-axis feeding downward, because the power used to lift the headstock upward is more than that used to balance out the headstock gravity when Z-axis is feeding downward.
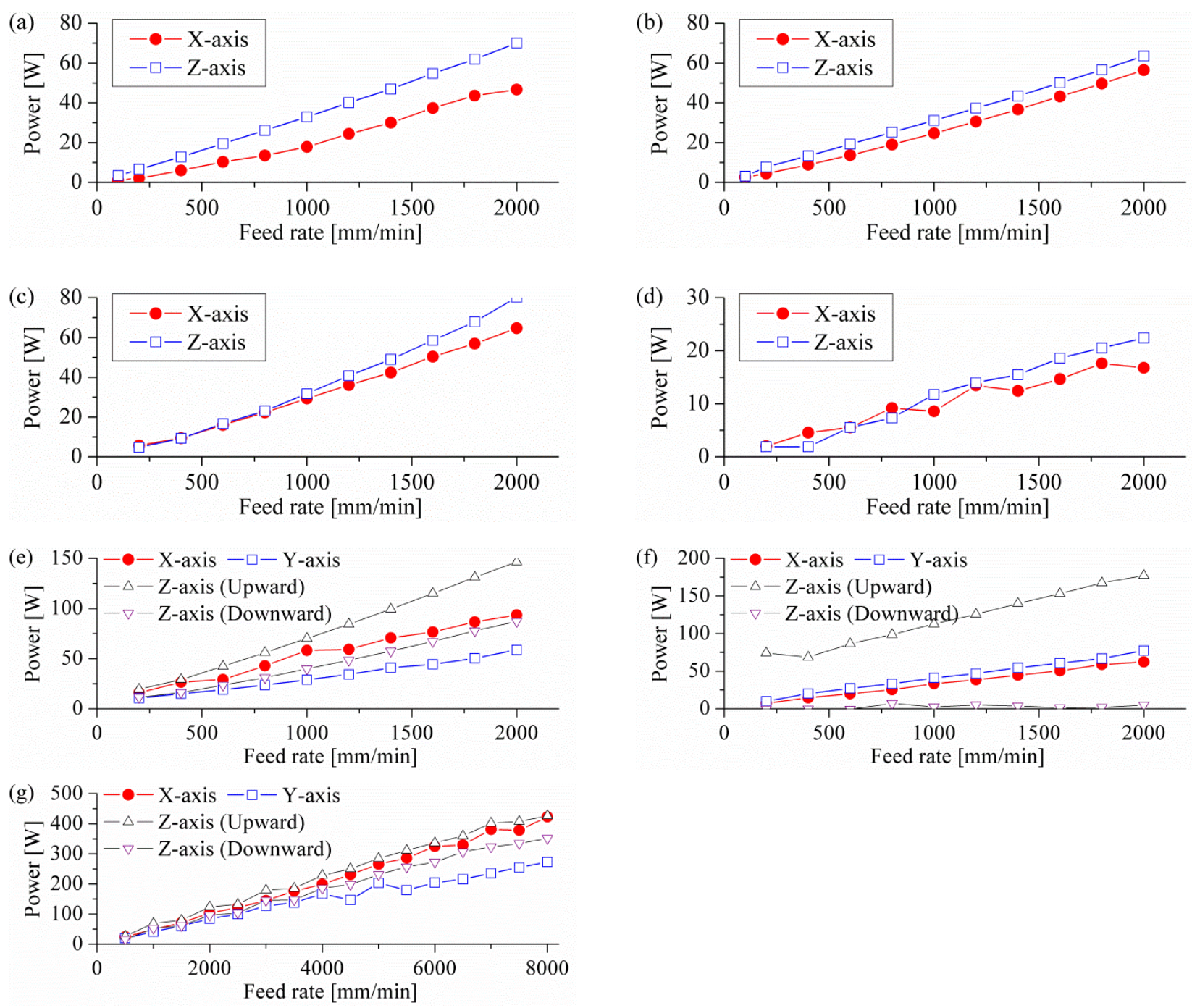

Fig. 5. Power of feeding at various feed rates: (a) CK6153i; (b) CK6136i; (c) CAK6150Di; (d) CY-K500; (e) JTVM6540; (f) XK715B; (g) XHK-714F. 
According to Equation (2), the feeding power models can be obtained by second order polynomial regression. Models for the feeding power are summarized in Table 12.

Table 12 Feeding power prediction models.

\begin{tabular}{|c|c|c|c|}
\hline $\begin{array}{l}\text { Machine } \\
\text { tool }\end{array}$ & Power models & $\begin{array}{l}\text { Machine } \\
\text { tool }\end{array}$ & Power models \\
\hline $\begin{array}{l}\text { CK6153 } \\
\text { i }\end{array}$ & $\begin{array}{l}P_{\mathrm{XF}}=5 \times 10^{-6} f_{\mathrm{r}}^{2}+0.0135 f_{\mathrm{r}}\left(0<f_{\mathrm{r}} \leq 2000\right) \\
P_{\mathrm{ZF}}=2 \times 10^{-6} f_{\mathrm{r}}^{2}+0.0311 f_{\mathrm{r}}\left(0<f_{\mathrm{r}} \leq 2000\right)\end{array}$ & CK6136i & $\begin{array}{ll}P_{\mathrm{XF}}=4 \times 10^{-6} f_{\mathrm{r}}^{2}+0.0211 \times f_{\mathrm{r}} & \left(0<f_{\mathrm{r}} \leq 2000\right) \\
P_{\mathrm{ZF}}=4 \times 10^{-8} f_{\mathrm{r}}^{2}+0.0314 \times f_{\mathrm{r}} & \left(0<f_{\mathrm{r}} \leq 2000\right)\end{array}$ \\
\hline $\begin{array}{l}\text { CAK61 } \\
\text { 50Di }\end{array}$ & $\begin{array}{ll}P_{\mathrm{XF}}=4 \times 10^{-6} f_{\mathrm{r}}^{2}+0.0253 \times f_{\mathrm{r}} & \left(0<f_{\mathrm{r}} \leq 2000\right) \\
P_{\mathrm{ZF}}=9 \times 10^{-6} f_{\mathrm{r}}^{2}+0.0227 \times f_{\mathrm{r}} & \left(0<f_{\mathrm{r}} \leq 2000\right)\end{array}$ & $\begin{array}{l}\text { CY-K50 } \\
0\end{array}$ & $\begin{array}{ll}P_{\mathrm{XF}}=-10^{-6} f_{\mathrm{r}}^{2}+0.0113 \times f_{\mathrm{r}} & \left(0<f_{\mathrm{r}} \leq 2000\right) \\
P_{\mathrm{ZF}}=10^{-6} f_{\mathrm{r}}^{2}+0.0095 \times f_{\mathrm{r}} & \left(0<f_{\mathrm{r}} \leq 2000\right)\end{array}$ \\
\hline $\begin{array}{l}\text { JTVM6 } \\
540\end{array}$ & $\begin{array}{ll}P_{\mathrm{XF}}=-7 \times 10^{-6} f_{\mathrm{r}}^{2}+0.0602 \times f_{\mathrm{r}} & \left(0<f_{\mathrm{r}} \leq 2000\right) \\
P_{\mathrm{YF}}=-2 \times 10^{-6} f_{\mathrm{r}}^{2}+0.0315 \times f_{\mathrm{r}} & \left(0<f_{\mathrm{r}} \leq 2000\right) \\
P_{\mathrm{ZF}}^{\mathrm{U}}=2 \times 10^{-6} f_{\mathrm{r}}^{2}+0.069 \times f_{\mathrm{r}} & \left(0<f_{\mathrm{r}} \leq 2000\right) \\
P_{\mathrm{ZF}}^{\mathrm{D}}=3 \times 10^{-6} f_{\mathrm{r}}^{2}+0.0371 \times f_{\mathrm{r}} & \left(0<f_{\mathrm{r}} \leq 2000\right)\end{array}$ & XK715B & $\begin{array}{ll}P_{\mathrm{XF}}=-10^{-6} f_{\mathrm{r}}^{2}+0.034 \times f_{\mathrm{r}} & \left(0<f_{\mathrm{r}} \leq 2000\right) \\
P_{\mathrm{YF}}=-4 \times 10^{-6} f_{\mathrm{r}}^{2}+0.0447 \times f_{\mathrm{r}} & \left(0<f_{\mathrm{r}} \leq 2000\right) \\
P_{\mathrm{ZF}}^{\mathrm{U}}=-4 \times 10^{-5} f_{\mathrm{r}}^{2}+0.156 \times f_{\mathrm{r}} & \left(0<f_{\mathrm{r}} \leq 2000\right) \\
P_{\mathrm{ZF}}^{\mathrm{D}}=-10^{-6} f_{\mathrm{r}}^{2}+0.0041 \times f_{\mathrm{r}} & \left(0<f_{\mathrm{r}} \leq 2000\right) \\
\end{array}$ \\
\hline $\begin{array}{l}\text { XHK-71 } \\
4 \mathrm{~F}\end{array}$ & $\begin{array}{ll}P_{\mathrm{XF}}=5 \times 10^{-7} f_{\mathrm{r}}^{2}+0.0491 \times f_{\mathrm{r}} & \left(0<f_{\mathrm{r}} \leq 8000\right) \\
P_{\mathrm{YF}}=-1 \times 10^{-6} f_{\mathrm{r}}^{2}+0.043 \times f_{\mathrm{r}} & \left(0<f_{\mathrm{r}} \leq 8000\right) \\
P_{\mathrm{ZF}}^{\mathrm{U}}=-5 \times 10^{-7} f_{\mathrm{r}}^{2}+0.059 \times f_{\mathrm{r}} & \left(0<f_{\mathrm{r}} \leq 8000\right) \\
P_{\mathrm{ZF}}^{\mathrm{D}}=-1 \times 10^{-7} f_{\mathrm{r}}^{2}+0.0461 \times f_{\mathrm{r}} & \left(0<f_{\mathrm{r}} \leq 8000\right)\end{array}$ & & \\
\hline
\end{tabular}

$f_{\mathrm{r}}$ : feed rate $[\mathrm{mm} / \mathrm{min}] ; P_{\mathrm{XF}}: \mathrm{X}$-axis feeding power $[\mathrm{W}] ; P_{\mathrm{YF}}$ : Y-axis feeding power $[\mathrm{W}] ; P_{\mathrm{ZF}}: \mathrm{Z}$-axis feeding power $[\mathrm{W}] ; P_{\mathrm{ZF}}^{\mathrm{U}}$ : Power of Z-axis feeding upward [W]; $P_{\mathrm{ZF}}^{\mathrm{D}}$ : Power of Z-axis feeding downward $[\mathrm{W}]$.

From above results, the power of non-cutting motions which include basic, auxiliary and air-cutting motions varies significantly among different machine tools. For air-cutting motions, the power is also dependent on the process parameters such as spindle rotational speed, feed rate, etc. The obtained spindle rotation and feeding power models can be used to calculate the energy consumption of CNC machine tools using given process parameters.

\subsection{Power of material removal motion}

In this paper, two types of material removal motions are selected for study: turning and milling. The turning tests are conducted on CK6153i, CK6136i and CAK6150Di CNC lathes, and the milling tests are conducted on JTVM6540 and XHK-714F. The power of turning and milling is discussed in the following sections. 


\subsubsection{Power of turning}

The turning power is shown and compared in Table 13. The turning power for the three selected machine tools is very close to each other for the same combination of cutting parameters, as shown in Fig. 6. It can be inferred that the turning power is only influenced by workpiece materials and cutting parameters, but rarely influenced by machine tools. Thus formulas obtained from one machine tool could be used to predict the cutting power of other machine tools. In order to verify this conjecture, each turning power model of the three machine tools was used to predict the turning power of other two machine tools.

Table 13 Cutting power data for turning and milling experiments.

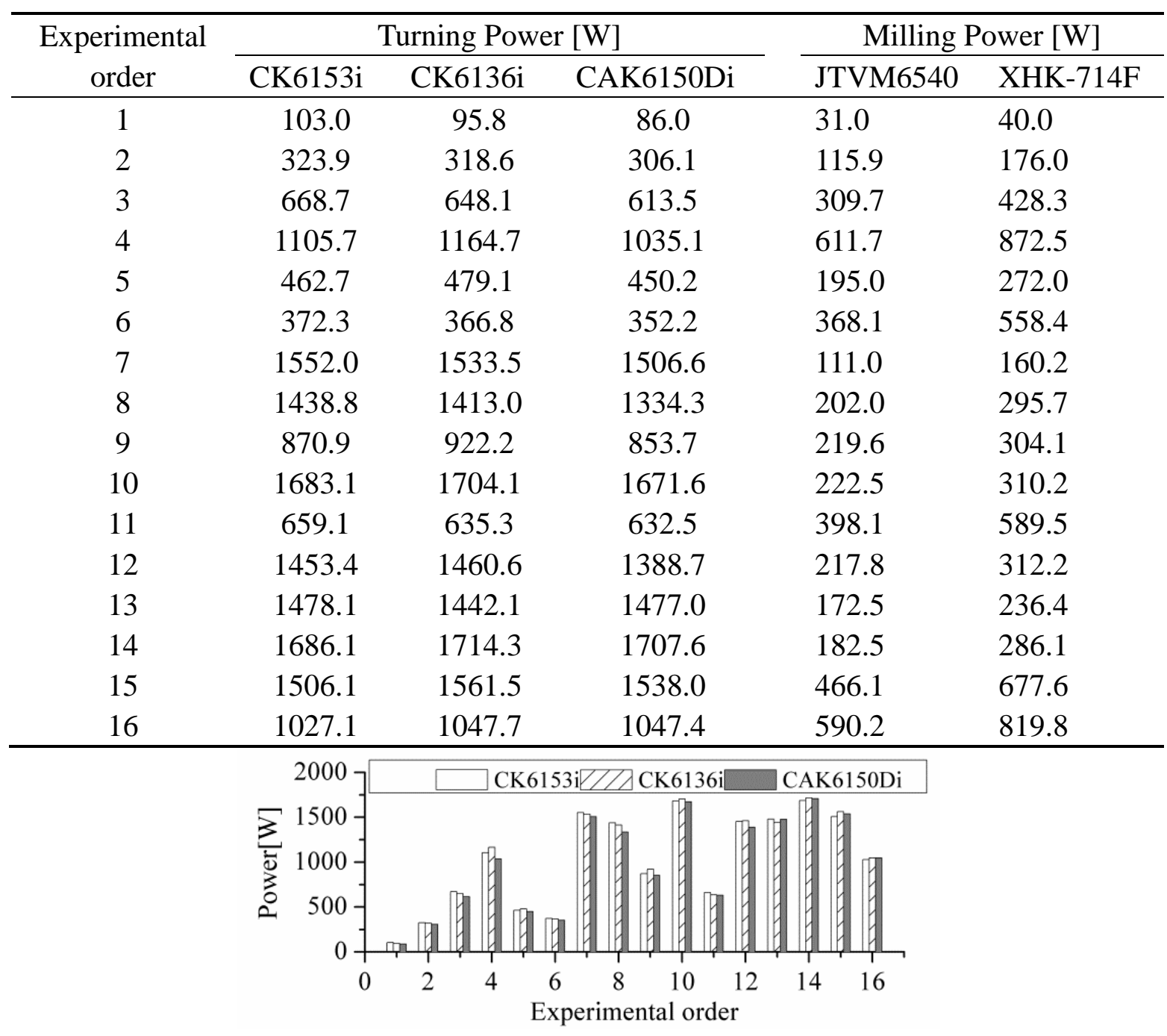

Fig. 6. Comparison of turning power among CK6153i, CK6136i and CAK6150Di CNC lathes. 
Using the experimental data in Table 13 and regression analysis in section 3.3, the turning power models were obtained and summarized in Table 14.

Table 14 Turning power prediction models.

\begin{tabular}{ll}
\hline Machine tool & Power models \\
\hline CK6153i & $P_{\mathrm{T}}=44.57 v^{0.909} f^{0.657} a_{\mathrm{p}}^{0.917}$ \\
CK6136i & $P_{\mathrm{T}}=40.64 v^{0.931} f^{0.662} a_{\mathrm{p}}^{0.941}$ \\
CAK6150Di & $P_{\mathrm{T}}=30.86 v^{0.984} f^{0.669} a_{\mathrm{p}}^{0.941}$ \\
\hline
\end{tabular}

The turning power model of CK6153i in Table 14 was used to predict the turning power of CK6136i and CAK6150Di. Here cutting parameters were taken from Table 7. The predicted and measured turning power values were compared, and the prediction accuracy Acc is defined as:

$$
\text { Acc }=1-\frac{\left|P_{\text {pred }}-P_{\text {mes }}\right|}{P_{\text {mes }}}
$$

Where, $P_{\text {pred }}$ is the predicted power [W], $P_{\text {mes }}$ is measured power [W].

The prediction accuracy of turning power model of CK6153i is shown in Fig. 7. The prediction accuracy in the first experiment is low, 79.5\% for CK6136i and 65.7\% for CAK6150Di. This can be explained by noting that the turning power is very small (less than $100 \mathrm{~W}$ ) and largely influenced by measurement errors in the first experiment. When the turning power is larger, the prediction accuracy becomes higher (above 90\%). The average prediction accuracy is $94.3 \%$ for CK6136i and 93.3\% for CAK6150Di.

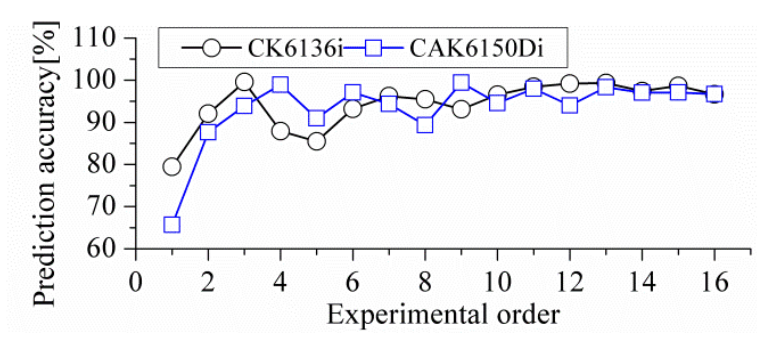

Fig. 7. Prediction accuracy of turning power model of CK6153i.

The turning power models of CK6136i and CAK6150Di in Table 14 were used by the same approach to verify their prediction accuracy, as shown in Fig. 8. For the turning power model of CK6136i, its average prediction accuracy is $95.0 \%$ for CK6153i and 93.0\% for CAK6150Di. For the turning power model of CAK6150Di, the values are 94.5\% for CK6153i and 94.1\% for CK6136i. 
The average prediction accuracy of the three cutting power models is all above $93 \%$.

Any one of the three models can be used to predict the turning power of the three selected CNC lathes. Thus for the same type of workpiece material, the turning power model can be obtained experimentally by one machine tool and applied to other machine tools.

(a)

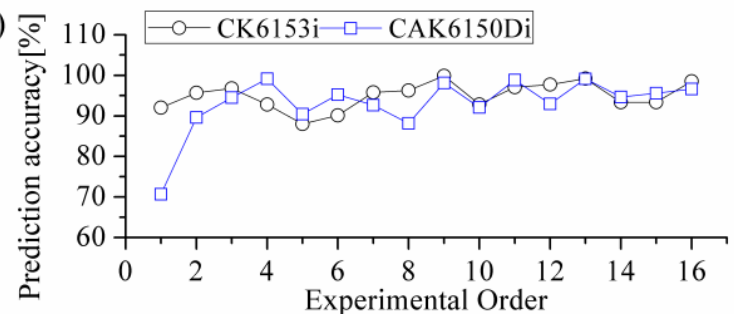

(b)

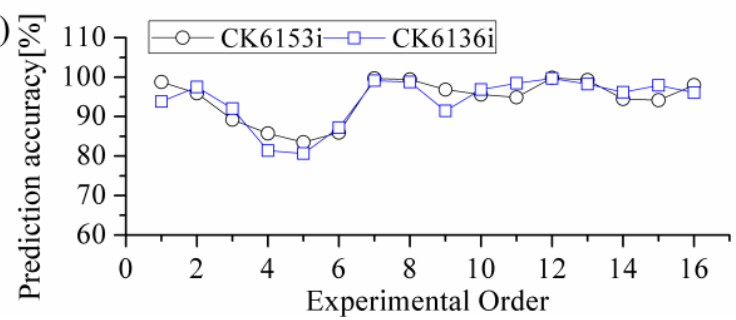

Fig. 8. Prediction accuracy of turning power models of (a) CK6136i (b) CAK6150Di.

\subsubsection{Power of milling}

The milling power data is shown in Table 13. It is observed that the milling power of $\mathrm{XHK}-714 \mathrm{~F}$ is obviously larger than that of JTVM6540 using the same combination of cutting parameters, as shown in Fig. 9. Using the experimental data in Table 13, the milling power models were obtained through regression analysis in section 3.3, as summarised in Table 15.

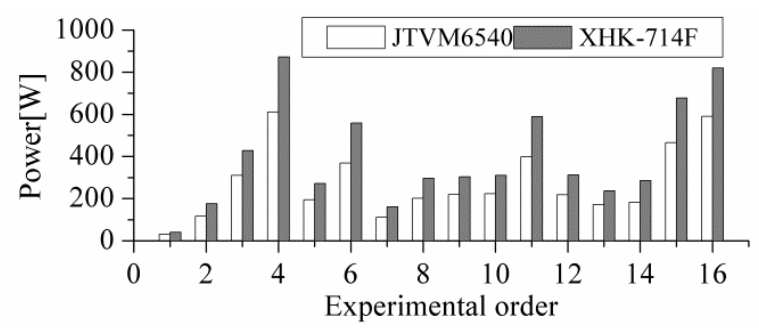

Fig. 9. Comparison of milling power between JTVM6540 and XHK-714F.

Table 15 Milling power prediction models.

\begin{tabular}{ll}
\hline Machine tool & Power models \\
\hline JTVM6540 & $P_{\mathrm{M}}=3.353 v^{0.927} f_{\mathrm{z}}^{0.764} a_{\mathrm{p}}^{0.927} a_{\mathrm{e}}{ }^{0.942}$ \\
XHK-714F & $P_{\mathrm{M}}=4.044 v^{0.958} f_{\mathrm{z}}^{0.798} a_{\mathrm{p}}{ }^{0.923} a_{\mathrm{e}}{ }^{1.000}$ \\
\hline
\end{tabular}

The milling power of XHK-714F is predicted using the milling power models of JTVM6540 in Table 15. The prediction accuracy is between $60 \%$ and $75 \%$, as shown in Fig. 10 (a). The average prediction accuracy is $70.0 \%$. Similarly, the power model of XHK-714F in Table 15 is used to 
predict the milling power of JTVM6540, as shown in Fig. 10 (b), and the average prediction accuracy is only $56.7 \%$. The power obtained from one milling machine achieves the accuracy below $70.0 \%$ for the prediction of milling power of other milling machines. Thus the milling power of each $\mathrm{CNC}$ milling machines need to be modeled separately.
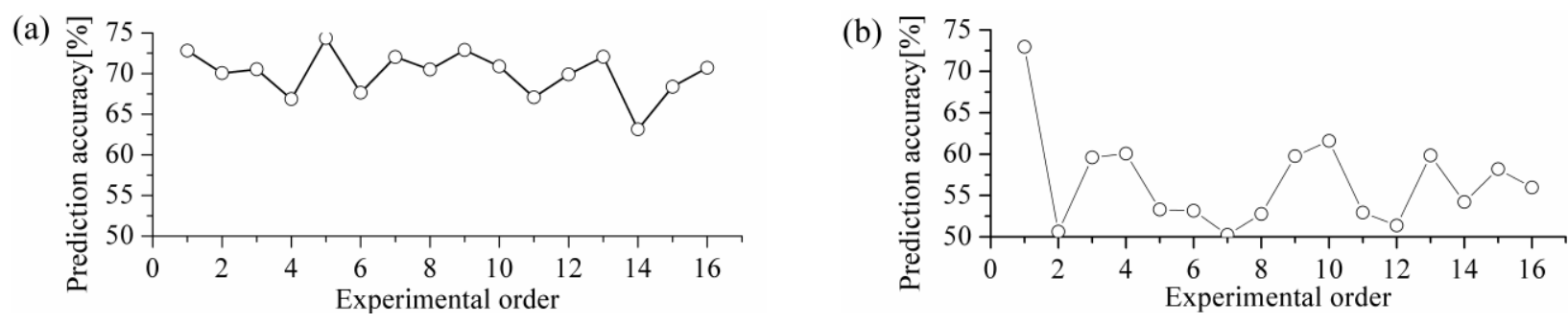

Fig. 10. Predicted accuracy of milling power models of (a) JTVM6540 (b) XHK-714F.

\subsection{Specific energy consumption and energy utilization rate}

Specific energy consumption (SEC) is defined as the energy consumption of the machine tool for removing $1 \mathrm{~cm}^{3}$ material (Kara and $\mathrm{Li}, 2011$ ). The SEC can be further decomposed into two segments according to whether the energy is used to remove the material: non-cutting related SEC and cutting related SEC. Kara and Li (2011) noted that the SEC is an inverse function of material removal rate (MRR). However, the influence of non-cutting and cutting related SEC was not investigated.

Take CK6153i for instance, the non-cutting and cutting power was measured for each cutting experiments using the cutting parameters in Table 7. Then the non-cutting or cutting related SEC was calculated using Equation (10).

$$
\mathrm{SEC}=\frac{P}{\mathrm{MRR}}
$$

Where, SEC is specific energy consumption $\left[\mathrm{J} / \mathrm{mm}^{3}\right], P$ is the non-cutting or cutting power [W], MRR is the material removal rate $\left[\mathrm{mm}^{3} / \mathrm{s}\right]$.

As shown In Fig. 11, the non-cutting and cutting related SEC are the function of MRR. The non-cutting power consumption do not increase much with the increase of MRR, as a result, the non-cutting related SEC decreases rapidly with the increase of MRR. The cutting related SEC do not decreases obviously with the increase of MRR for the reason that the cutting power increase 
proportionally with MRR. Thus the main chance for energy decreasing lies in the decrease of non-cutting energy consumption of machine tools.

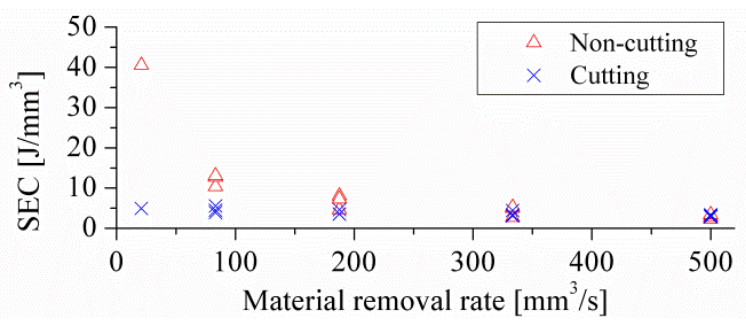

Fig. 11. Non-cutting and cutting related SEC as a function of MRR.

In order to compare the efficiency of energy usage with different MRR, energy utilization rate, which is defined as the ratio of the energy used for material removal to the total energy consumption, is introduced and represented as the function of MRR in this paper, as shown in Fig. 12. As the MRR increases, the energy utilization rate increases, from $10.9 \%$ at the MRR of $20.8 \mathrm{~mm}^{3} / \mathrm{s}$ to the maximum of $57.9 \%$ at the MRR of $500 \mathrm{~mm}^{3} / \mathrm{s}$. Therefore, the energy consumption of machining processes can be greatly reduced by increasing cutting parameters.

Noting that the maximum energy utilization rate is only $57.9 \%$, a large amount of energy could be saved by reducing non-cutting energy. The energy saving potential lies in two aspects: reducing the non-cutting time during machine tool use phase and designing more energy efficient machine tools. For instance, the machine tool should be shut down if the waiting time is too long. The machine tool manufactures could adopt lightweight transmission structure to reduce the spindle rotation power, or use minimum quantity lubrication to reduce cutting fluid spraying power.

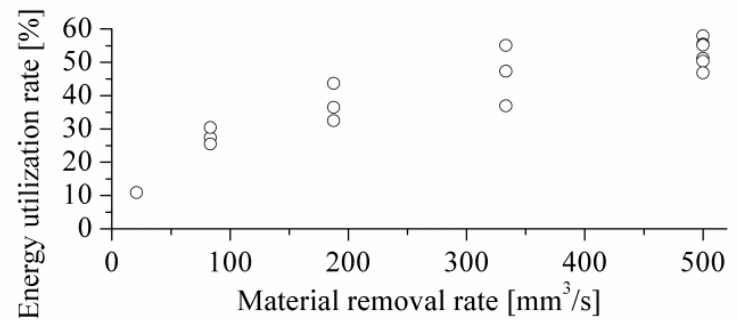

Fig. 12. Energy utilization rate as the function of MRR. 


\section{Conclusions}

CNC machine tools are widely used in manufacturing industry and consume lots of energy. Understanding energy consumption characteristics provides the basis for energy saving of CNC machine tools. There has been some research on theoretical modeling and analysis of CNC machine tools energy consumption. However, energy characteristics may vary a lot for different types of CNC machine tools due to the complexity of machine tool structure.

The motion of CNC machine tool is the root cause of energy consumption. The motions are divided into four types: basic motion, auxiliary motion, air-cutting motion and material removal. Four CNC lathes, two CNC milling machines and a vertical milling center are selected for study. Power data of different motions for the selected machine tools was measured and compared in this paper. Based on the obtained data, power models of air-cutting motion and material removal were established by regression analysis. According to experimental results, conclusions are drawn as follows:

1. The power consumption of basic, auxiliary and air-cutting motions is dependent on machine tools.

2. The power consumption of turning is almost independent from the machine tools, and the model obtained from one machine tool can be used to predict the turning power of other machine tools. However, the power consumption of milling varies with different machine tools, the milling power of each machine tool needs to be modeled separately.

3. With the increase of MRR, the non-cutting related SEC decreases rapidly while the cutting related SEC decreases slightly. The main chance for energy reduction lies in the decrease of non-cutting energy consumption of machine tools.

4. The energy utilization rate of machining processes is very low, especially when MRR is low. Thus large amount of energy could be saved by increasing cutting parameters.

The power data and models can help gain insight into the energy consumption characteristics and constitution of CNC machine tools. Energy saving direction of CNC machine tools was further pointed out in this paper. Based on the power data and models of machine tool motions, energy saving methodologies of $\mathrm{CNC}$ machine tools during their use phase will be developed in future. 


\section{Acknowledgement}

This work was supported by the National Natural Science Foundation of China (Grant No.51175464) and the Ningbo Science and Technology Innovation Team (Grant No. 2011B81006). The authors would like to convey their sincere thanks to Mr. Yang Kaidong from Tsinghua University, Mr. Shao Saijun from The University of Hong Kong, Mr. Zhou Jilie and Mr. Wang Qiang from the metalworking center of Zhejiang University for their valuable contributions during the experiments. We also thank all the anonymous reviewers for their helpful suggestions on the quality improvement of our paper.

\section{Nomenclature}

Acc prediction accuracy

$a_{\mathrm{e}} \quad$ width of cut $[\mathrm{mm}]$,

$A_{\mathrm{e}} \quad$ logarithmic transformation of $a_{\mathrm{e}}$

$a_{\mathrm{p}} \quad$ depth of cut [mm]

$A_{\mathrm{p}} \quad$ logarithmic transformation of $a_{\mathrm{p}}$

$C \quad$ constant in the spindle rotation power model

$C_{1} \quad$ coefficient for feeding power

$C_{2} \quad$ coefficient for feeding power

$C_{\mathrm{M}} \quad$ coefficient for milling power

$c_{\mathrm{M}} \quad$ logarithmic transformation of $C_{\mathrm{M}}$

$C_{\mathrm{T}} \quad$ coefficient for turning power

$c_{\mathrm{T}} \quad$ logarithmic transformation of $C_{\mathrm{T}}$

$f \quad$ feed $[\mathrm{mm} / \mathrm{r}]$

$F \quad$ logarithmic transformation of $f$

$f_{r} \quad$ feed rate $[\mathrm{mm} / \mathrm{min}]$

$f_{\mathrm{z}} \quad$ feed per tooth [mm/tooth]

$F_{\mathrm{z}} \quad$ logarithmic transformation of $f_{\mathrm{z}}$

$m \quad$ coefficient of spindle rotational speed

MRR the material removal rate $\left[\mathrm{mm}^{3} / \mathrm{s}\right.$ ]

$n \quad$ spindle rotational speed [ $\mathrm{r} / \mathrm{min}]$

$n_{\mathrm{M}} \quad$ coefficient of feed rate per tooth in milling power model

$n_{\mathrm{T}} \quad$ coefficient of cutting speed in turning power model

$P \quad$ the non-cutting or cutting power [W]

$P_{\mathrm{SR}}^{\mathrm{AH}} \quad$ Spindle rotation power for AH transmission chain [W]

$P_{\mathrm{SR}}^{\mathrm{AL}} \quad$ Spindle rotation power for AL transmission chain [W]

$P_{\mathrm{SR}}^{\mathrm{BH}} \quad$ Spindle rotation power for $\mathrm{BH}$ transmission chain [W]

$\mathrm{P}_{\mathrm{SR}}^{\mathrm{BL}} \quad$ Spindle rotation power for BL transmission chain [W]

$P_{\mathrm{FD}} \quad$ axis feeding power [W] 


$\begin{array}{ll}P_{\mathrm{SR}}^{\mathrm{H}} & \text { Spindle roation power for } \mathrm{H} \text { transmission chain [W] } \\ P_{\mathrm{M}} & \text { milling power [W] } \\ p_{\mathrm{M}} & \text { logarithmic transformation of } P_{\mathrm{M}} \\ P_{\mathrm{mes}} & \text { measured power [W] } \\ P_{\mathrm{pred}} & \text { the predicted power [W] } \\ P_{\mathrm{SR}}^{\mathrm{M}} & \text { Spindle rotation power for M transmission chain [W] } \\ P_{\mathrm{SR}}^{\mathrm{L}} & \text { Spindle rotation power for L transmission chain [W] } \\ P_{\mathrm{SR}} & \text { spindle rotation power [W] } \\ P_{\mathrm{T}} & \text { turning power [W] } \\ p_{\mathrm{T}} & \text { logarithmic transformation of } P_{\mathrm{T}} \\ P_{\mathrm{XF}} & \text { X-axis feeding power [W] } \\ P_{\mathrm{YF}} & \text { Y-axis feeding power [W] } \\ P_{\mathrm{ZF}} & \text { Z-axis feeding power [W] } \\ P_{\mathrm{ZF}}^{\mathrm{D}} & \text { Power of Z-axis feeding downward [W] } \\ P_{\mathrm{ZF}}^{\mathrm{U}} & \text { Power of Z-axis feeding upward [W] } \\ \mathrm{SEC} & \left.\text { specific energy consumption [J/mm }{ }^{3}\right], \\ u_{\mathrm{M}} & \text { coefficient of width of cut in milling power model } \\ v & \text { cutting speed [m/min] } \\ V & \text { logarithmic transformation of } v \\ x_{\mathrm{T}} & \text { coefficient of depth of cut in turning power model } \\ x_{M} & \text { coefficient of depth of cut in milling power model } \\ y_{\mathrm{T}} & \text { coefficient of feed rate in turning power model } \\ y_{\mathrm{M}} & \text { coefficient of feed rate per tooth in milling power model }\end{array}$

\section{References}

Ai, X., Xiao, S., 1994. Concise manual of cutting parameters. Machine Press, Beijing, China (in Chinese).

Avram, O.I., Xirouchakis, P., 2011. Evaluating the use phase energy requirements of a machine tool system. J. Clean. Prod. 19, 699-711.

Balogun, V.A., Mativenga, P.T., 2013. Modelling of direct energy requirements in mechanical machining processes. J. Clean. Prod. 41, 179-186.

Behrendt, T., Zein, A., Min, S., 2012. Development of an energy consumption monitoring procedure for machine tools. CIRP Ann. Manuf. Tech. 61, 43-46.

Bhushan, R.K., 2013. Optimization of cutting parameters for minimizing power consumption and maximizing tool life during machining of $\mathrm{Al}$ alloy $\mathrm{SiC}$ particle composites. J. Clean. Prod. 39, 242-254.

Dahmus, J.B., Gutowski, T.G., 2004. An environmental analysis of machining, ASME Inter. Mech. Eng. Congr. R\&D Expos. ASME, Anaheim, CA, United states, pp. 643-652. 
Ding, T., Zhang, S., Wang, Y., Zhu, X., 2010. Empirical models and optimal cutting parameters for cutting forces and surface roughness in hard milling of AISI H13 steel. Int. J. Adv. Manuf. Tech. 51, 45-55.

Hanafi, I., Khamlichi, A., Mata Cabrera, F., Almansa, E., Jabbouri, A., 2012. Optimization of cutting conditions for sustainable machining of PEEK-CF30 using TiN tools. J. Clean Prod. 33, 1-9.

He, Y., Liu, F., Wu, T., Zhong, F.P., Peng, B., 2012. Analysis and estimation of energy consumption for numerical control machining. Proc. Inst. Mech. Eng. Part B J. Eng. Manuf. 226, 255-266.

Jia, S., Tang, R., Lv, J., 2014. Therblig-based energy demand modeling methodology of machining process to support intelligent manufacturing. J Intell Manuf. 25, 913-931..

Kalpakjian, S., 1984. Manufacturing processes for engineering materials. Addison-Wesley Publishing Company, Reading, massachusetts, USA.

Kalpakjian, S., Schmid, S., 2006. Manufacturing engineering and technology, 5th ed. Pearson Education, Massachusetts, USA.

Kara, S., Li, W., 2011. Unit process energy consumption models for material removal processes. CIRP Ann. Manuf. Tech. 60, 37-40.

Knight, W., Boothroyd, G., 2006. Fundamentals of Metal Machining and Machine Tools, 3nd ed. CRC Press, New York, USA.

Li, W., Kara, S., 2011. An empirical model for predicting energy consumption of manufacturing processes: a case of turning process. Proc. Inst. Mech. Eng. Part B J. Eng. Manuf. 225, 1636-1646.

Li, W., Zein, A., Kara, S., Herrmann, C., 2011. An investigation into fixed energy consumption of machine tools, 18th CIRP International Conference on Life Cycle Engineering: Glocalized Solutions for Sustainability in Manufacturing. Springer, Braunschweig, Germany, pp. 268-273.

Li, X.-R., 2014. Development Status of Domestic CNC Machine Tools. Hunan Agricultural Machinery 41, 79-80.

Li, Y., He, Y., Wang, Y., Yan, P., Liu, X., 2013. A framework for characterising energy consumption of machining manufacturing systems. Int J Prod Res. 52, 314-325.

Lv, J., Tang, R., Jia, S., 2014. Therblig-based energy supply modeling of computer numerical control machine tools. J. Clean. Prod. 65, 168-177.

Mouzon, G., Yildirim, M.B., Twomey, J., 2007. Operational methods for minimization of energy consumption of manufacturing equipment. Int J Prod Res. 45, 4247-4271.

Murray, V.R., Zhao, F., Sutherland, J.W., 2012. Life cycle analysis of grinding: a case study of non-cylindrical computer numerical control grinding via a unit-process life cycle inventory approach. Proc. Inst. Mech. Eng. Part B J. Eng. Manuf. 226, 1604-1611. 
NBS, 2011. China Energy Statistics Yearbook 2011. China Statistics Press, Beijing, China (in Chinese).

Rao, P.N., 2000. Manufacturing Technology: Metal Cutting and Machine Tools. McGraw-Hill Education, New York, USA.

Santos, J.P., Oliveira, M., Almeida, F.G., Pereira, J.P., Reis, A., 2011. Improving the environmental performance of machine-tools: influence of technology and throughput on the electrical energy consumption of a press-brake. J. Clean. Prod. 19, 356-364. 